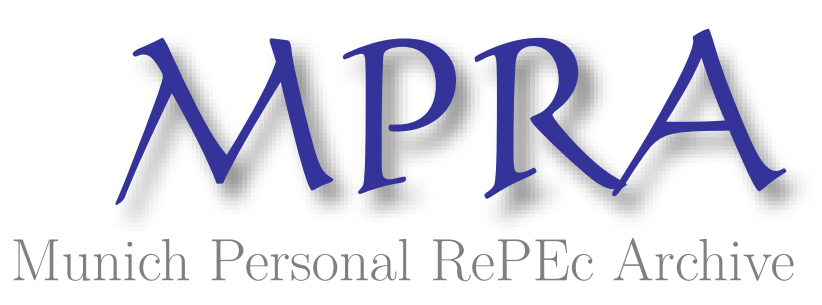

\title{
Demographic Change and Political Polarization in the United States
}

Boxell, Levi

Stanford University

24 March 2018

Online at https://mpra.ub.uni-muenchen.de/85589/

MPRA Paper No. 85589, posted 29 Mar 2018 17:39 UTC 


\title{
Demographic Change and Political Polarization in the United States
}

\author{
Levi Boxell, Stanford University*
}

March 2018

\begin{abstract}
I construct an index of political polarization using seven previously proposed measures. I estimate the relative propensity for polarization across demographic groups in a regression framework and examine the extent to which demographic change can explain recent trends in polarization. Assuming fixed propensities for polarization, I estimate that 25 to 59 percent of the change in polarization between 1984 and 2016 can be attributed to demographic change in the United States.
\end{abstract}

*E-mail: lboxell@stanford.edu. I thank Matthew Gentzkow and Jesse M. Shapiro for their comments and suggestions. I acknowledge funding from the National Science Foundation (grant number: DGE-1656518) and the Institute for Humane Studies. The American National Election Studies and the relevant funding agencies bear no responsibility for use of the data or for interpretations or inferences based upon such uses. 


\section{Introduction}

The popular narrative and many academic studies suggest that the United States' electorate is becoming increasingly polarized. In 1994, 23 percent of Republicans were more liberal than the median Democrat and 17 percent of Democrats were more conservative than the median Republican based on an aggregation of ten policy questions. In 2017, only 1 percent of Republicans were more liberal than the median Democrat and only 3 percent of Democrats were more conservative than the median Republican (Kiley 2017). Favorable feelings towards the opposing party are also at all time lows in recent years (Iyengar et al. 2012; Gentzkow 2016).

Who or what is driving contemporary US political polarization? Numerous answers have been proposed for this question. These answers include, among others, Republicans or conservatives (Ornstein 2014), rising income inequality (McCarty et al. 2008), the rise in foreign trade (Autor et al. 2016), cable television (Martin and Yurukoglu 2017), the internet and social media (Sunstein 2017), increased ethnic diversity (Abramowitz 2014), and changing religious beliefs (Abramowitz 2014). In this paper, I examine the extent to which demographic change can explain recent trends in political polarization.

The United States has become increasingly educated and older in the last few decades (Ryan and Bauman 2016; Shrestha and Heisler 2011). Both of these demographic characteristics are highly correlated with political participation (Timpone 1998), and education is related to greater ideological prejudice (Henry and Napier 2017). To examine the impact of these and related demographic changes, I take seven measures used in Boxell et al. (2017), modify them so that they can be constructed separately for demographic groups of interest, and construct an index of polarization from these modified measures. The index of polarization increased by 35 percent between 1984 and 2016. I then use a regression framework to estimate the relative propensities for polarization across six different demographic categories: religious affiliation, work and income status, education, race, age, and gender. The regression framework controls for the fact that certain demographic groups may have higher rates of polarization because their affiliation is highly correlated with being a member of another demographic group.

This allows me to construct an estimate of the counterfactual level of polarization if propensities for polarization were held constant at their 1984 levels but the demographic composition of the United States were allowed to vary. I find that demographic change can explain 34 percent of the change in the index of political polarization. For the individual polarization measures, estimates range between 25 and 59 percent, with over a third of the change in partisan affect 
being accounted for by demographic change.

This work relates to a growing literature on political polarization. Much of the previous work has focused on documenting and debating whether polarization is increasing (e.g., Abramowitz and Saunders 2008; Fiorina and Abrams 2008; Fiorina et al. 2010; Lelkes 2016). Other research examines how the different measures of political polarization are related to each other (Mason 2015). Closest to this study is the work that examines the causes of political polarization. Previous work has examined the role of media (Prior 2013), income inequality (McCarty et al. 2008), international trade (Autor et al. 2016), and elite polarization (Fiorina and Abrams 2008).

This paper also relates to work using demographic differences to examine the credibility of proposed causes for political outcomes. Recent work use demographic differences in propensities to use the internet to argue that the internet is unlikely to be driving contemporary mass political polarization or to have altered the 2016 election outcome (Hampton and Hargittai 2016; Boxell et al. 2017; Boxell et al. 2018). Some work has begun to look at differential polarization rates among Republicans and Democrats and argue the answer varies based on the measure used (Doherty 2014).

\section{Data and polarization measures}

The data come from the American National Election Studies (ANES) 1948-2012 Cumulative Data file and the ANES 2016 Time Series study. The ANES studies are nationally representative surveys that ask demographic and political questions. For consistency across years, I drop internet-based surveys that were conducted in 2012 and 2016, thus, restricting attention to faceto-face surveys. I also drop observations with missing or non-valid responses to any of the demographic questions used in section 3 and restrict the data to presidential election years. Throughout, I weight responses using the type-0, face-to-face survey weights (VCF0009x) for respondents in 1996-2012 and the post-election, face-to-face survey weights (V160102f) for 2016 respondents.

I use seven measures taken from Boxell et al. (2017) and modify them so that they can be constructed at the individual respondent level. ${ }^{1}$ I first construct a measure of the 'warmth' of feelings one has towards one's own party or ideological group on a scale of $0-100$ relative to the

\footnotetext{
${ }^{1}$ Boxell et al. (2017) were not the first to use these or related measures. See references therein for previous uses. One measure from Boxell et al. (2017), issue divergence, is not used.
} 
opposing group. Partisan affect polarization is the difference between an individuals feelings towards their own party and that of the opposing party. For independents, the absolute value of the difference in feelings towards the two parties is used. I define a similar measure to measure relative warmth of feelings for one's own ideology using the difference between an individual's feelings towards their own ideological group and the opposing ideological group. Again, for moderates, the absolute value of the difference between the two groups is used.

The next measure, partisan sorting, measures the extent to which an individual's party and ideological affiliations are aligned weighted by the strength of these affiliations. Similarly, I can measure the strength of ideological beliefs. Ideological polarization is the strength of an individual's self-placed ideological affiliation measured from 0 to 3 . Another measure examines the extent to which respondent's perceive there to be ideological differences between Republicans and Democrats. Perceived partisan-ideology polarization is the difference between an individual's placement of Republicans and Democrats on a 7-point liberal-to-conservative ideological scale.

I also measure the extent to which individuals have consistent beliefs ideologically across a range of six policy questions that include, among others, questions on abortion and government defense spending. ${ }^{2}$ Issue consistency measures the extent to which an individual gives ideologically consistent responses to a set of six policy questions. Each response is labelled as conservative (1), moderate (0), or liberal (-1) and the absolute value of the sum of their responses indicates an individual's degree of ideological consistency. Finally, straight-ticket voting is an indicator for whether an individual reported voting for the same party (Republican or Democratic) in both the presidential and House elections. ${ }^{3}$

Given these seven measures of political polarization, I construct a single index as follows. I normalize each of the seven measures by its standard deviation using respondents in 1984 with non-missing values for the polarization measure. I then take the average of these normalized measures to create an index defined at the individual level. Formally, for each individual $i$, I set

$$
\mathcal{M}_{i}=\frac{1}{|M|} \sum_{m \in M} \frac{m_{i}}{\sigma_{m}}
$$

where $\sigma_{m}$ is the standard deviation of the measure $m$ across respondents in 1984. Then for each measure (including the index), the weighted mean of the measure across respondents in year

\footnotetext{
${ }^{2}$ Relative to Boxell et al. (2017), I drop the question related to government provision of health insurance to decrease the number of missing responses.

${ }^{3}$ See Online Appendix for the formal definition of each of these measures.
} 
$t$ gives the value of the measure for a given year. ${ }^{4}$ By design, the index has been increasing steadily since 1984 and increased 35 percent over the entire period.

\section{Results}

I examine differential propensities for polarization across six demographic categories: work and income status, religious affiliation, education levels, age, gender, and race. To control for intergroup correlations, I first estimate the following linear conditional mean model via weighted OLS

$$
\mathbb{E}(\mathcal{M} \mid X)=X \cdot \beta
$$

where $\mathcal{M}$ is a measure of polarization and $X$ is a vector of indicators for various demographic characteristics ${ }^{5}$ with coefficients $\beta$.

I estimate equation (1) on two different samples: the first sample containing responses from the 1984 and 1988 ANES surveys with estimates $\hat{\beta}_{1984}$ and the second containing responses from the 2012 and 2016 ANES surveys with estimates $\hat{\beta}_{2016}{ }^{6}$ For brevity, I refer to the first sample as the 1984 sample and the second sample as the 2016 sample.

The fact that the United States has become increasingly educated and older suggests that demographic change may be responsible for some of the recent growth in political polarization. To examine the role of demographic change, I estimate the counterfactual scenario where propensities for polarization are fixed at their 1984 level but demographic characteristics are allowed to vary between 1984 and 2016

$$
\tilde{\mathcal{M}}_{2016}^{1984}=\bar{X}_{2016} \cdot \hat{\beta}^{\prime}{ }_{1984}
$$

where $\bar{X}_{2016}$ is the weighted average for each indicator across the 2016 sample and $\hat{\beta}_{1984}^{\prime}$ is the estimates from equation (1) over the 1984 sample. Then $\frac{\tilde{\mathcal{M}}_{2016}^{1984}-\tilde{\mathcal{M}}_{1984}^{1984}}{\tilde{\mathcal{M}}_{2016}^{2016}-\mathcal{\mathcal { M }}_{1984}^{1984}}$ is an estimate of the proportion of the overall change in polarization between 1984 and 2016 that can be accounted for by demographic change.

\footnotetext{
${ }^{4}$ Note that, for the construction of the index for an individual $i$, the mean is taken across polarization measures with non-missing responses. Then, separately for each polarization measure (including the index), the sample is restricted to individuals with nonmissing responses to the polarization measure. Thus, the exact sample changes across measures.

${ }^{5}$ See the Online Appendix for the set of demographic indicators and their construction. Of course, one indicator for each demographic category is dropped to avoid collinearity in estimation.

${ }^{6}$ See the Online Appendix for coefficient estimates.
} 
Table 1 reports the estimates of this ratio for the index and each of the individual polarization measure, along with bootstrapped 95 percent confidence intervals. I estimate that 34 percent of the change in the index can be explained by demographic change. The estimates of the individual polarization measures range from 25 percent for the measure of issue consistency to 59 percent for the measure of ideological polarization. For partisan affect, a frequently used measure of polarization, over a third of the change can be attributed to demographic change. In all cases, the 95 percent confidence intervals exclude demographic change explaining 0 percent of the change in polarization.

Figure 1 uses each year separately and examines how the counterfactual level of polarization has varied with the true predicted level of polarization between 1984 and 2016 for the index and each individual polarization measure. Across all measures, the counterfactual level of polarization has been steadily increasing upwards along with the increase in the true predicted level of polarization. There is no clear break in either trend suggesting a relatively stable growth in polarization induced by demographic change.

\section{Discussion and Conclusion}

The above analysis assumes a political center and defines polarization as deviations from this center. For some polarization measures, this choice of center is arbitrary and different choices of "center" may give different counterfactual estimates. For other measures, such as partisan affect, the choice of center is well-defined and thus, less subject to this critique. The fact that the estimates for partisan affect align well with the overall index is reassuring.

The counterfactual analysis also assumes that polarization propensities across demographic groups are fixed at their 1984 levels. However, changing demographic composition may make certain demographic groups more or less extreme in response to perceived threats. To the extent to which demographic change increases polarization propensities, as some have suggested (Abramowitz 2014), my estimates are conservative.

I show that demographic change may explain a nontrivial proportion of the recent rise in political polarization. This has two immediate implications. First, there is a smaller amount of polarization that needs to be explained by other mechanisms. Second, as demographics continue to shift towards demographic groups with higher propensities for polarization, we should expect the current upward trends in polarization to likewise continue. 


\section{References}

Abramowitz, Alan I. and Kyle L. Saunders. 2008. Is polarization a myth? Journal of Politics. 70(2): 542-555.

Abramowitz, Alan I. 2014. How race and religion have polarized American voters. The Washington Post. Accessed at https://www.washingtonpost.com/news/monkey-cage/wp/2014/01/20/howrace-and-religion-have-polarized-american-voters/?utm_term=.ca88f64553ca on November $18,2017$.

Autor, David, David Dorn, Gordon Hanson, and Kaveh Majlesi. 2016. Importing political polarization? The electoral consequences of rising trade exposure. Working paper. Accessed at https://economics.mit.edu/files/11665 on October 26, 2017.

Boxell, Levi, Matthew Gentzkow, and Jesse M. Shapiro. 2017. Greater internet use is not associated with faster growth in political polarization among US demographic groups. Proceedings of the National Academy of Sciences. 114(40): 10612-10617.

Boxell, Levi, Matthew Gentzkow, and Jesse M. Shapiro. 2018. A note on internet use and the 2016 election outcome. Working paper.

Doherty, Carroll. 2014. Which party is more to blame for political polarization? It depends on the measure. Pew Research Center. Accessed at http://www.pewresearch.org/fact$\operatorname{tank} / 2014 / 06 / 17 /$ which-party-is-more-to-blame-for-political-polarization-it-depends-on-themeasure/ on November 21, 2017.

Fiorina, Morris P. and Samuel J. Abrams. 2008. Political polarization in the American public. Annual Review of Political Science. 11: 563-588.

Fiorina, Morris P., Samuel J. Abrams, and Jeremy C. Pope. 2010. Culture war? The myth of polarized America. London, England: Longman Publishing.

Gentzkow, Matthew. 2016. Polarization in 2016. Toulouse Network for Information Technology Whitepaper. Accessed at http://web.stanford.edu/ gentzkow/research/PolarizationIn2016.pdf on February 19, 2017.

Hampton, Keith N. and Eszter Hargittai. 2016. Stop blaming Facebook for Trump's election win. TheHill.com. Accessed at http://thehill.com/blogs/pundits-blog/presidentialcampaign/307438-stop-blaming-facebook-for-trumps-election-win on October 26, 2017.

Henry, PJ and Jaime L. Napier. 2017. Education is related to greater ideological prejudice. Public Opinion Quarterly. 81(4):930-942.

Iyengar, Shanto, Gaurav Sood, and Yphtach Lelkes. 2012. Affect, not ideology: A social identity perspective on polarization. Public Opinion Quarterly. 76(3):405-431.

Kiley, Jocelyn. 2017. In polarized era, fewer Americans hold a mix of conservative and liberal views. Pew Research Center. Accessed at http://www.pewresearch.org/fact-tank/2017/10/23/inpolarized-era-fewer-americans-hold-a-mix-of-conservative-and-liberal-views/ on Novem- 
ber 18, 2017.

Lelkes, Yphtach. 2016. Mass polarization: Manifestations and measurements. Public Opinion Quarterly. 80(S1):392-410.

Martin, Gregory J. and Ali Yurukoglu. 2017. Bias in cable news: Persuasion and polarization. American Economic Review. 107(9):2565-2599.

Mason, Lilliana. 2015. "I disrespectfully agree": The differential effects of partisan sorting on social and issue polarization. American Journal of Political Science. 59(10):128-145.

McCarty, Nolan, Keith T. Poole, and Howard Rosenthal. 2008. Polarized America: The dance of ideology and unequal riches. MIT Press: Cambridge, MA.

Ornstein, Norm. 2014. Yes, polarization is asymmetric-and conservatives are worse. The Atlantic. Accessed at https://www.theatlantic.com/politics/archive/2014/06/yes-polarizationis-asymmetric-and-conservatives-are-worse/373044/ on November 18, 2017.

Prior, Markus. 2013. Media and political polarization. Annual Review of Political Science. 16:101-127.

Ryan, Camille L. and Kurt Bauman. 2016. Educational attainment in the United States: 2015. Census: Current Population Reports. Accessed at https://www.census.gov/content/dam/Census/library/publications/2016/demo/p20-578.pdf on November 18, 2017.

Shrestha, Laura B. and Elayne J. Heisler. 2011. The changing demographic profile of the United States. Congressional Research Service. Accessed at https://fas.org/sgp/crs/misc/RL32701.pdf on November 21, 2017.

Sunstein, Cass R. 2017. \#Republic: Divided democracy in the age of social media. Princeton University Press: Princeton, NJ.

Timpone, Richard J. 1998. Structure, behavior, and voter turnout in the United States. American Political Science Review. 91(1):145-158. 
Figure 1: Counterfactual polarization levels
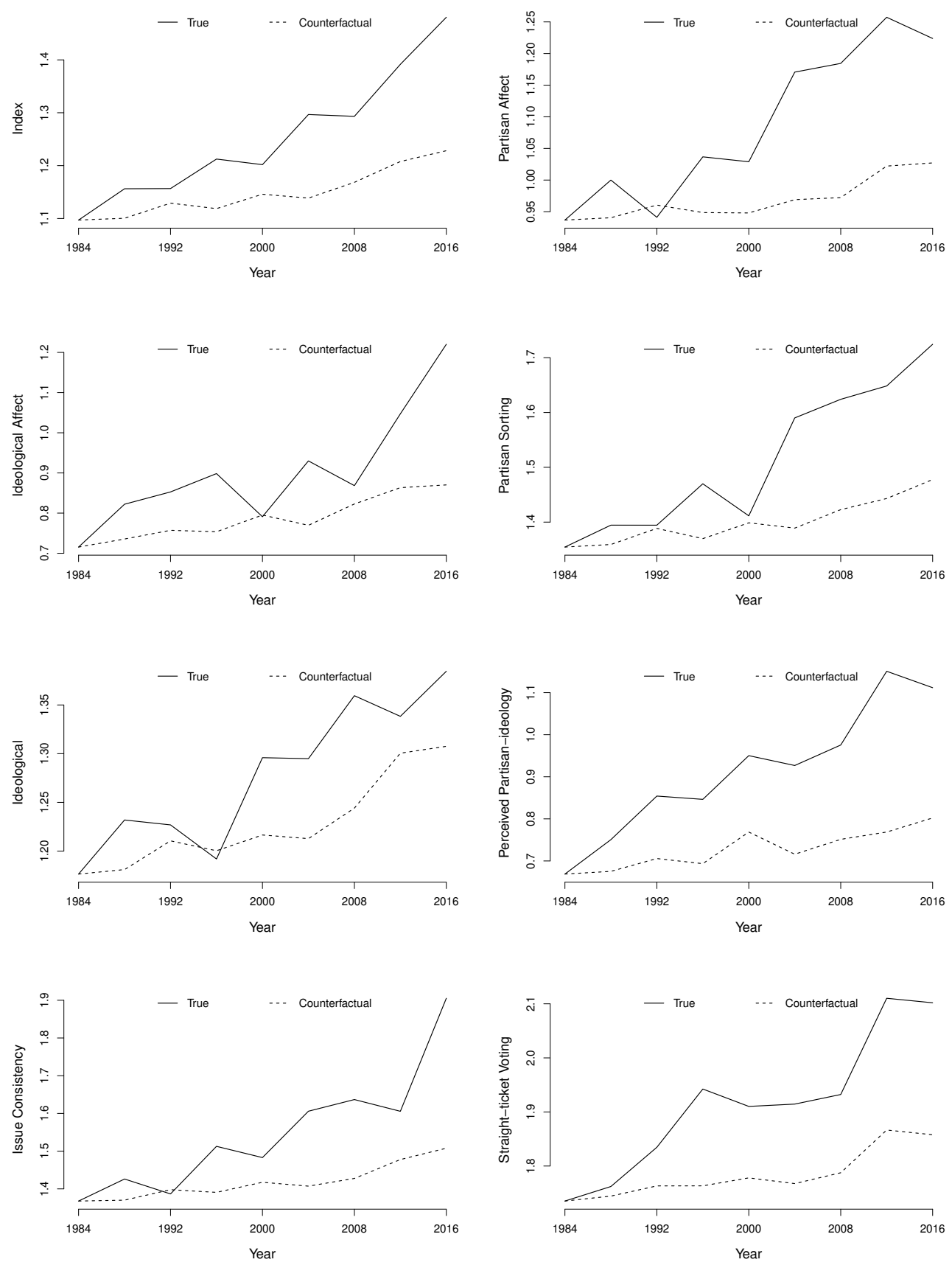

Notes: Figure plots the the true predicted levels and counterfactual levels of polarization between 1984 and 2016 for each polarization measure. For each year from 1984 through 2016, the plot reports the true predicted level of polarization (solid) given each year's coefficient estimates and demographic composition along with the counterfactual level (dashed) if propensities for polarization were kept at their 1984 levels but the demographic decomposition is allowed to vary. In contrast to table 1, each year is used separately. See main text for additional details on the construction of each measure and the counterfactuals. 
Table 1: Impact of demographic change on polarization, 1984-2016

\begin{tabular}{lcc}
\hline Measures & Change in polarization due to demographic change & 95\% CI \\
\hline Index & 0.34 & $(0.23,0.45)$ \\
Partisan Affect & 0.34 & $(0.16,0.53)$ \\
Ideological Affect & 0.33 & $(0.13,0.54)$ \\
Partisan Sorting & 0.28 & $(0.08,0.48)$ \\
Ideological & 0.59 & $(0.17,1.01)$ \\
Perceived Partisan-ideology & 0.27 & $(0.18,0.36)$ \\
Issue Consistency & 0.25 & $(0.08,0.43)$ \\
Straight-ticket Voting & 0.31 & $(0.14,0.48)$ \\
\hline
\end{tabular}

Notes: Table shows, for each measure, the estimated proportion of the change in the polarization measure that is attributable to changes in demographics between 1984-1988 and 2012-2016 as outlined in section 3. The 95 percent confidence intervals are constructed from the standard errors of a nonparametric bootstraps of 100 replicates sampled at the year level. See the Online Appendix for additional details on the nonparametric bootstrap procedure. 


\title{
Online Appendix for
}

\section{Demographic Change and Political Polarization in the United States}

\author{
Levi Boxell, Stanford University*
}

March 2018

\section{List of Tables}

S1 Relative propensities for polarization, $1984 \ldots \ldots \ldots \ldots$. . . . . . . 2

S2 Relative propensities for polarization, $2016 \ldots \ldots \ldots$

\section{Contents}

1 Polarization Measure Details 4

2 Demographic Indicator Details $\quad 4$

3 Bootstrap Details 5

*E-mail: lboxell@stanford.edu. I thank Matthew Gentzkow and Jesse M. Shapiro for their comments and suggestions. I acknowledge funding from the National Science Foundation (grant number: DGE-1656518) and the Institute for Humane Studies. The American National Election Studies and the relevant funding agencies bear no responsibility for use of the data or for interpretations or inferences based upon such uses. 
Table S1: Relative propensities for polarization, 1984

\begin{tabular}{|c|c|c|c|c|c|c|c|c|}
\hline & $\begin{array}{c}(1) \\
\text { Index }\end{array}$ & $\begin{array}{c}(2) \\
\text { Partisan } \\
\text { Affect }\end{array}$ & $\begin{array}{c}\text { (3) } \\
\text { Ideological } \\
\text { Affect }\end{array}$ & $\begin{array}{c}(4) \\
\text { Partisan } \\
\text { Sorting }\end{array}$ & $\begin{array}{c}\text { (5) } \\
\text { Ideological }\end{array}$ & $\begin{array}{c}\text { (6) } \\
\text { Perceived }\end{array}$ & $\begin{array}{c}(7) \\
\text { Issue } \\
\text { Consist. }\end{array}$ & $\begin{array}{c}(8) \\
\text { Straight- } \\
\text { Ticket }\end{array}$ \\
\hline \multirow[t]{2}{*}{ Intercept } & 1.13 & 1.29 & 0.39 & 1.36 & 1.21 & 0.55 & 1.46 & 1.97 \\
\hline & $(0.06)$ & $(0.10)$ & $(0.11)$ & $(0.10)$ & $(0.10)$ & $(0.10)$ & $(0.10)$ & $(0.13)$ \\
\hline \multirow[t]{2}{*}{ Income: Middle } & 0.06 & 0.03 & 0.17 & 0.01 & -0.02 & 0.10 & 0.06 & 0.10 \\
\hline & $(0.03)$ & $(0.05)$ & $(0.06)$ & $(0.05)$ & $(0.05)$ & $(0.05)$ & $(0.05)$ & $(0.07)$ \\
\hline \multirow[t]{2}{*}{ Income: Top } & 0.08 & -0.02 & 0.22 & 0.11 & 0.00 & 0.22 & 0.03 & -0.08 \\
\hline & $(0.03)$ & $(0.06)$ & $(0.06)$ & $(0.06)$ & $(0.06)$ & $(0.06)$ & $(0.06)$ & $(0.08)$ \\
\hline \multirow[t]{2}{*}{ Gender: Males } & 0.06 & 0.05 & 0.11 & 0.07 & 0.16 & 0.03 & 0.02 & 0.08 \\
\hline & $(0.03)$ & $(0.04)$ & $(0.05)$ & $(0.04)$ & $(0.04)$ & $(0.04)$ & $(0.04)$ & $(0.05)$ \\
\hline \multirow[t]{2}{*}{ Race: Other } & -0.08 & -0.33 & 0.14 & -0.10 & 0.00 & 0.11 & -0.07 & -0.35 \\
\hline & $(0.06)$ & $(0.10)$ & $(0.11)$ & $(0.10)$ & $(0.10)$ & $(0.09)$ & $(0.09)$ & $(0.14)$ \\
\hline \multirow[t]{2}{*}{ Race: White } & -0.01 & -0.37 & 0.19 & 0.07 & -0.03 & 0.23 & 0.05 & -0.27 \\
\hline & $(0.04)$ & $(0.07)$ & $(0.08)$ & $(0.07)$ & $(0.07)$ & $(0.07)$ & $(0.07)$ & $(0.10)$ \\
\hline \multirow[t]{2}{*}{ Religion: Jewish } & -0.05 & -0.09 & -0.13 & -0.07 & -0.10 & 0.01 & -0.14 & 0.14 \\
\hline & $(0.08)$ & $(0.13)$ & $(0.15)$ & $(0.14)$ & $(0.14)$ & $(0.13)$ & $(0.13)$ & $(0.17)$ \\
\hline \multirow[t]{2}{*}{ Religion: Other } & 0.15 & 0.06 & 0.23 & 0.11 & 0.23 & 0.11 & 0.24 & 0.16 \\
\hline & $(0.05)$ & $(0.07)$ & $(0.08)$ & $(0.07)$ & $(0.07)$ & $(0.07)$ & $(0.07)$ & $(0.10)$ \\
\hline \multirow[t]{2}{*}{ Religion: Protestant } & 0.05 & -0.03 & 0.14 & 0.09 & 0.10 & -0.00 & 0.13 & -0.05 \\
\hline & $(0.03)$ & $(0.05)$ & $(0.05)$ & $(0.05)$ & $(0.05)$ & $(0.05)$ & $(0.05)$ & $(0.06)$ \\
\hline \multirow[t]{2}{*}{ Education: HS or less } & -0.33 & -0.18 & -0.40 & -0.41 & -0.23 & -0.48 & -0.39 & -0.15 \\
\hline & $(0.03)$ & $(0.05)$ & $(0.06)$ & $(0.05)$ & $(0.05)$ & $(0.05)$ & $(0.05)$ & $(0.06)$ \\
\hline \multirow[t]{2}{*}{ Education: Some college } & -0.16 & -0.11 & -0.14 & -0.22 & -0.18 & -0.19 & -0.16 & -0.10 \\
\hline & $(0.03)$ & $(0.05)$ & $(0.06)$ & $(0.06)$ & $(0.06)$ & $(0.05)$ & $(0.05)$ & $(0.07)$ \\
\hline \multirow[t]{2}{*}{ Employment: Not in workforce } & 0.12 & 0.27 & 0.10 & 0.15 & 0.13 & 0.08 & -0.05 & 0.19 \\
\hline & $(0.03)$ & $(0.06)$ & $(0.06)$ & $(0.06)$ & $(0.06)$ & $(0.06)$ & $(0.06)$ & $(0.07)$ \\
\hline \multirow[t]{2}{*}{ Employment: Unemployed } & 0.05 & 0.08 & 0.00 & 0.04 & 0.01 & 0.04 & -0.01 & 0.30 \\
\hline & $(0.06)$ & $(0.09)$ & $(0.11)$ & $(0.09)$ & $(0.09)$ & $(0.09)$ & $(0.09)$ & $(0.14)$ \\
\hline \multirow[t]{2}{*}{ Age Group: 40-64 } & 0.09 & 0.10 & 0.16 & 0.05 & -0.01 & 0.10 & 0.02 & 0.10 \\
\hline & $(0.03)$ & $(0.04)$ & $(0.05)$ & $(0.04)$ & $(0.04)$ & $(0.04)$ & $(0.04)$ & $(0.06)$ \\
\hline \multirow[t]{2}{*}{ Age Group: $65+$} & 0.12 & 0.06 & 0.25 & 0.14 & 0.00 & 0.18 & -0.04 & -0.01 \\
\hline & $(0.05)$ & $(0.07)$ & $(0.08)$ & $(0.08)$ & $(0.07)$ & $(0.07)$ & $(0.07)$ & $(0.09)$ \\
\hline Observations & 2661 & 2613 & 2276 & 2661 & 2661 & 2441 & 2637 & 1556 \\
\hline$R^{2}$ & 0.07 & 0.03 & 0.06 & 0.04 & 0.02 & 0.08 & 0.04 & 0.03 \\
\hline
\end{tabular}

Notes: Table shows the coefficients and standard errors for various weighted OLS regressions. Across all polarization measures, the sample is restricted to observations in 1984 and 1988. Each independent variable is an indicator and the polarization measure is the dependent variable. See main text for additional details on the construction of the polarization measure and choice of weights. See below for additional details on the construction of the demographic indicators. 
Table S2: Relative propensities for polarization, 2016

\begin{tabular}{|c|c|c|c|c|c|c|c|c|}
\hline & $\begin{array}{c}(1) \\
\text { Index }\end{array}$ & $\begin{array}{c}\text { (2) } \\
\text { Partisan } \\
\text { Affect }\end{array}$ & $\begin{array}{c}(3) \\
\text { Ideological } \\
\text { Affect }\end{array}$ & $\begin{array}{c}(4) \\
\text { Partisan } \\
\text { Sorting }\end{array}$ & $\begin{array}{c}\text { (5) } \\
\text { Ideological }\end{array}$ & $\begin{array}{c}\text { (6) } \\
\text { Perceived }\end{array}$ & $\begin{array}{c}\text { (7) } \\
\text { Issue } \\
\text { Consist. }\end{array}$ & $\begin{array}{c}(8) \\
\text { Straight- } \\
\text { Ticket }\end{array}$ \\
\hline \multirow[t]{2}{*}{ Intercept } & 1.19 & 1.46 & 0.54 & 1.27 & 1.12 & 0.91 & 1.18 & 2.22 \\
\hline & $(0.07)$ & $(0.11)$ & $(0.13)$ & $(0.13)$ & $(0.11)$ & $(0.10)$ & $(0.12)$ & $(0.09)$ \\
\hline \multirow[t]{2}{*}{ Income: Middle } & 0.13 & 0.04 & 0.20 & 0.08 & 0.07 & 0.19 & 0.20 & 0.05 \\
\hline & $(0.04)$ & $(0.06)$ & $(0.07)$ & $(0.07)$ & $(0.06)$ & $(0.05)$ & $(0.06)$ & $(0.06)$ \\
\hline \multirow[t]{2}{*}{ Income: Top } & 0.17 & 0.01 & 0.20 & 0.07 & 0.14 & 0.28 & 0.26 & 0.01 \\
\hline & $(0.04)$ & $(0.07)$ & $(0.08)$ & $(0.08)$ & $(0.07)$ & $(0.06)$ & $(0.07)$ & $(0.06)$ \\
\hline \multirow[t]{2}{*}{ Gender: Males } & -0.00 & -0.04 & 0.02 & -0.04 & 0.05 & -0.07 & 0.10 & -0.00 \\
\hline & $(0.03)$ & $(0.05)$ & $(0.05)$ & $(0.06)$ & $(0.05)$ & $(0.04)$ & $(0.05)$ & $(0.04)$ \\
\hline \multirow[t]{2}{*}{ Race: Other } & -0.03 & -0.41 & 0.10 & 0.11 & -0.08 & 0.25 & 0.22 & -0.18 \\
\hline & $(0.07)$ & $(0.10)$ & $(0.11)$ & $(0.11)$ & $(0.10)$ & $(0.08)$ & $(0.10)$ & $(0.09)$ \\
\hline \multirow[t]{2}{*}{ Race: White } & 0.08 & -0.54 & 0.37 & 0.28 & -0.06 & 0.41 & 0.41 & -0.13 \\
\hline & $(0.06)$ & $(0.08)$ & $(0.10)$ & $(0.10)$ & $(0.09)$ & $(0.07)$ & $(0.09)$ & $(0.07)$ \\
\hline \multirow[t]{2}{*}{ Religion: Jewish } & 0.11 & 0.20 & -0.01 & 0.24 & 0.13 & 0.17 & 0.11 & -0.15 \\
\hline & $(0.10)$ & $(0.15)$ & $(0.17)$ & $(0.17)$ & $(0.15)$ & $(0.13)$ & $(0.15)$ & $(0.11)$ \\
\hline \multirow[t]{2}{*}{ Religion: Other } & -0.01 & -0.00 & -0.02 & 0.08 & 0.10 & 0.03 & -0.11 & 0.01 \\
\hline & $(0.04)$ & $(0.06)$ & $(0.07)$ & $(0.07)$ & $(0.06)$ & $(0.05)$ & $(0.06)$ & $(0.05)$ \\
\hline \multirow[t]{2}{*}{ Religion: Protestant } & 0.12 & 0.14 & 0.12 & 0.17 & 0.15 & -0.01 & 0.20 & -0.05 \\
\hline & $(0.04)$ & $(0.06)$ & $(0.07)$ & $(0.07)$ & $(0.06)$ & $(0.05)$ & $(0.06)$ & $(0.05)$ \\
\hline \multirow[t]{2}{*}{ Education: HS or less } & -0.21 & -0.05 & -0.12 & -0.26 & -0.15 & -0.49 & -0.17 & -0.04 \\
\hline & $(0.04)$ & $(0.06)$ & $(0.07)$ & $(0.07)$ & $(0.06)$ & $(0.05)$ & $(0.06)$ & $(0.05)$ \\
\hline \multirow[t]{2}{*}{ Education: Some college } & -0.15 & 0.03 & -0.11 & -0.30 & -0.18 & -0.19 & -0.20 & 0.01 \\
\hline & $(0.04)$ & $(0.06)$ & $(0.07)$ & $(0.07)$ & $(0.06)$ & $(0.05)$ & $(0.06)$ & $(0.05)$ \\
\hline \multirow[t]{2}{*}{ Employment: Not in workforce } & 0.08 & 0.07 & -0.02 & 0.11 & 0.11 & 0.17 & 0.09 & 0.02 \\
\hline & $(0.04)$ & $(0.06)$ & $(0.07)$ & $(0.07)$ & $(0.06)$ & $(0.05)$ & $(0.06)$ & $(0.05)$ \\
\hline \multirow[t]{2}{*}{ Employment: Unemployed } & 0.00 & 0.01 & 0.07 & 0.05 & 0.27 & -0.11 & -0.19 & -0.08 \\
\hline & $(0.07)$ & $(0.11)$ & $(0.13)$ & $(0.13)$ & $(0.11)$ & $(0.10)$ & $(0.12)$ & $(0.10)$ \\
\hline \multirow[t]{2}{*}{ Age Group: 40-64 } & 0.12 & 0.24 & 0.14 & 0.22 & 0.16 & -0.17 & -0.01 & 0.04 \\
\hline & $(0.04)$ & $(0.05)$ & $(0.06)$ & $(0.06)$ & $(0.06)$ & $(0.05)$ & $(0.06)$ & $(0.05)$ \\
\hline \multirow[t]{2}{*}{ Age Group: $65+$} & 0.25 & 0.41 & 0.42 & 0.32 & 0.33 & -0.16 & 0.07 & 0.01 \\
\hline & $(0.05)$ & $(0.08)$ & $(0.09)$ & $(0.09)$ & $(0.08)$ & $(0.07)$ & $(0.08)$ & $(0.06)$ \\
\hline Observations & 1953 & 1933 & 1799 & 1953 & 1953 & 1877 & 1930 & 1139 \\
\hline$R^{2}$ & 0.08 & 0.05 & 0.05 & 0.05 & 0.03 & 0.12 & 0.07 & 0.01 \\
\hline
\end{tabular}

Notes: Table shows the coefficients and standard errors for various weighted OLS regressions. Across all polarization measures, the sample is restricted to observations in 2012 and 2016. Each independent variable is an indicator and the polarization measure is the dependent variable. See main text for additional details on the construction of the polarization measure and choice of weights. See below for additional details on the construction of the demographic indicators. 


\section{Polarization Measure Details}

Denote an individual $i$ 's party and ideological alignment as $P_{i}$ and $B_{i}$, respectively, which range from -3 (strong Democrat or liberal) to 3 (strong Republican or conservative). ${ }^{1}$ Let $R=\{i$ : $\left.P_{i}>0\right\}$ denote the set of Republican respondents and define $D$ analogously. Similarly, I let $C=\left\{i: B_{i}>0\right\}$ denote the set of conservative respondents and define $L$ analogously. The formal definition of each of the individual polarization measures are:

1. Partisan affect for individual $i$ is $\mathbf{1}_{i \in R}\left(A_{i}^{R}-A_{i}^{D}\right)+\mathbf{1}_{i \in D}\left(A_{i}^{D}-A_{i}^{R}\right)+\mathbf{1}_{i \notin R \cup D}\left|A_{i}^{D}-A_{i}^{R}\right|$.

2. Ideological affect for individual $i$ is $\mathbf{1}_{i \in C}\left(A_{i}^{C}-A_{i}^{L}\right)+\mathbf{1}_{i \in L}\left(A_{i}^{L}-A_{i}^{C}\right)+\mathbf{1}_{i \notin C \cup L}\left|A_{i}^{L}-A_{i}^{C}\right|$.

3. Partisan sorting for individual $i$ is $\left(6-\left|P_{i}-B_{i}\right|\right)\left(\left|P_{i}\right|+1\right)\left(\left|B_{i}\right|+1\right)$.

4. Ideological polarization for individual $i$ is $\left|B_{i}\right|$.

5. Perceived partisan-ideology polarization for individual $i$ is $\tilde{R}_{i}-\tilde{D}_{i}$, where $\tilde{R}_{i}$ denotes individual $i$ 's perception on how conservative Republicans are on a 7-point liberal-toconservative scale and $\tilde{D}_{i}$ is defined analogously.

6. Issue consistency for individual $i$ is $\left|\sum_{k \in K} k_{i}\right|$, where $K$ denotes the set of policy questions and, for each $k \in K, k_{i}$ denotes a conservative (1), moderate (0), or liberal (-1) response to that question from respondent $i$.

7. Straight-ticket voting is an indicator for whether individual $i$ reported voting for the same party (Republican or Democratic) in both the presidential and House elections.

\section{Demographic Indicator Details}

I give a brief summary of the construction of the demographic indicators below. See ANES codebooks for exact question wording and changes in wording over the years. See replication code for exact construction.

1. Income Groups: For the pre-2016 data, I use VCF0114 to construct the income groups which asks about family income before taxes and breaks it down into percentiles. The bottom third income is the 0-33 percentile groups; the middle third income is the 34-67 percentile groups; the top third income is the 68-100 percentile groups. For the 2016 data, I use V161361x to construct the income groups. The bottom third income is defined to be income less than $\$ 35,000$; the middle third income is defined to be income between $\$ 35,000$ and $\$ 79,999$; the top third income is defined to be income greater than or equal to $\$ 80,000$.

2. Work Status: For the pre-2016 data, I use VCF0116 to construct the work status indicators. Unemployed is defined to be those who indicate they are "temporarily laid off" or "unemployed." Employed is defined to be those who indicate they are "working now." Not in workforce is defined to be those who indicate they are "retired," "permanently

\footnotetext{
${ }^{1}$ See main text and SI of Boxell et al. (2017) along with the ANES survey codebooks for details on the questions used to construct each variable used in the polarization measures.
} 
disabled," "homemaker," or "student." For the 2016 data, I use V161277 which has the same coding as VCF0116.

3. Ideology: For the pre-2016 data, I use VCF0803 which asks respondents to place themselves on a liberal-conservative scale from 1 to 7 . I define liberals as those who place themselves as 1 or 2; moderates as those who place themselves as 3, 4, or 5; and conservatives as those who place themselves as 6 or 7. For the 2016 data, I use V61126 which has the same coding as VCF0803.

4. Party: For the pre-2016 data, I use VCF0301 which asks respondents whether they identify as Republican, Democratic, or Independent, and if Independent, whether they lean towards a given party. I define the party indicators according to the responses identifying each party and include leaners as Independents. For the 2016 data, I use V161158x which has the same coding as VCF0301. Note that the inclusion of leaners as Independents differs slightly from how the affect polarization measures define party affiliates.

5. Religion: For the pre-2016 data, I use VCF0128 which collapses previous questions regarding religious preferences into four categories: Protestant, Catholic (Roman Catholic), Jewish, and Other/none. I create an indicator for each of these categories. For the 2016 data, I use V161247a and V161247b which I code the same as VCF0128.

6. Education: For the pre-2016 data, I use VCF0110 which asks respondents the amount of education they've completed. High school or less is defined as those who complete 12 or fewer grades; some college is defined as those who complete 13 grades or more but no college degree; college graduate is defined as those who have a college or advanced degree. For the 2016 data, I use V161270. High school or less is defined as those who complete 12 or fewer grades; some college is defined as those who state having some college but no degree; college graduate is defined as those who have an associates, bachelors, masters, professional, or doctorate degree.

7. Age group: For the pre-2016 data, I use VCF0101. For the 2016 data, I use V161267.

8. Gender: For the pre-2016 data, I use VCF0104. For the 2016 data, I use V161002.

9. Race: For the pre-2016 data, I use VCF0105b which use interviewer observation of race in early samples and respondent identification of race in later samples. I define white as "White non-Hispanic" responses; black as "Black non-Hispanic" responses; and other as "Hispanic" or "Other or multiple races, non-Hispanic" responses. For the 2016 data, I use V161310x which asks respondents their racial identity. I define white as "White, non-Hispanic" responses; black as "Black, non-Hispanic" responses; and other as "Hispanic," "Asian, native Hawaiian, or other Pacific Islander, non-Hispanic," "Native American or Alaska Native, non-Hispanic," or "Other non-Hispanic including multiple races" responses.

\section{Bootstrap Details}

To construct each bootstrap sample, I sample (separately for each year) with replacement all observations with non-missing demographic indicators and use the polarization measures as 
constructed from the original sample. I then use these samples to construct the populationlevel measure of polarization, the demographic-based changes in polarization, the difference in demographic-based changes in polarization, and the proportion of the change in polarization explained by demographic change. Standard errors are then computed by taking the standard deviation of the values across the 100 bootstrap replicates. 